УДК $81 ' 373.422+81 ' 374.73+811.111$

DOI: 10.33184/YVDK-2021-04-30.41

Т.М. Воронина (доц. УрФУ, г. Екатеринбург), Д.А. Черноскутова (студ. УрФУ, г. Екатеринбург)

\title{
АНТОНИМИЧЕСКИЕ ЛАКУНЫ ПРИ ХАРАКТЕРИСТИКЕ ИНТЕЛЛЕКТУАЛЬНЫХ СВОЙСТВ ЛИЧНОСТИ В АНГЛИЙСКОМ ЯЗЫКЕ И ИХ ФРАЗЕОЛОГИЧЕСКАЯ КОМПЕНСАЦИЯ
}

Исследование выполнено при финансовой поддержке РФФИ (проект № 19-012-00458 «Отношения тождества и противоположности: интеграция ментальных пространств в лексикографическом, структурно-семантическом и когнитивнодискурсивном освещении»)

В статье рассматриваются антонимические пары слов, характеризующие интеллектуальные свойства личности в английском языке (talented - untalented, clever - stupid, sane-mad, reasonable - unreasonable, quick-witted - slow-witted, intelligentunintelligent, wise-foolish). Выявленные антонимические гнезда анализируются с точки зрения наличия лакунарных единии и фразеологизмов, способных быть средством компенсации лакун.

Ключевые слова: лексика интеллекта, английский язык, антонимы, фразеологизмы,, лакунарность, идеографический словарь

The article is devoted to the consideration of antonym pairs of lexemes that characterize the intellectual properties in the English language (talented- untalented, clever- stupid, sane- mad, reasonable - unreasonable, quick-witted - slow-witted, intelligentunintelligent, wise - foolish). The identified word formation nests of opposed pairs of words are analyzed in terms of the presence of lacunae and phraseological units capable of compensating for gaps.

Key Words: intelligence vocabulary, English, antonyms, phraseological units, lacunarity, conceptual dictionary 
Языковая картина мира, ее признаки и особенности значимый объект изучения в современной лингвистике; ее рассмотрение осуществляется прежде всего на основе анализа лексической и фразеологической семантики. Объектом данного исследования выступает семантика оппозитивных лексикофразеологических единиц, характеризующих интеллектуальные свойства человека в английском языке. Предметом является внутриязыковая лексическая лакунарность в английском языке. Материал - лексика денотативно-идеографической группы «Интеллектуальные свойства личности», а также фразеологические единицы (далее - ФЕ), способные быть средством заполнения выявленных лакун.

Лакуны традиционно подразделяются на межъязыковые и внутриязыковые. В нашем исследовании мы обратились к последним. И.А. Стернин указывает, что «в каждом языке существует большое количество внутриязыковых лакун, то есть пустых, не заполненных мест в лексико-фразеологической системе языка, хотя близкие по значению лексемы могут присутствовать» [Стернин 1998: 60]. Использование анализа антонимических пар и гнезд является продуктивным подходом при выявлении «пустых клеток» внутри одного языка [Быкова 2003]. Исследователи считают, что одной из значимых характеристик фразеологизмов выступает антонимичность, что позволяет рассматривать их как возможные пленусы при элиминировании «белых пятен», т.е. достраивании пробелов в языковом сознании [Кшеновская 2016: 161].

Как отмечается во многих работах, поле «Интеллект» содержит два полюса, которые оппозитивно характеризуют интеллектуальные способности человека [см, например: Стойкович 2013: 147]. Так, денотативно-идеографическая группа интеллектуальных свойств человека в английском языке представлена двумя оппозитивными ядерными значениями ys/intelligence и глуnocmb/stupidity. При категоризации умственных свойств человека в английском языке Д.Ю. Дронь заключает, что в британской лингвокультуре умный человек характеризуется как наделенный сверхспособностями, хитрый, сообразительный и ловкий, мудрый, образованный и обучаемый. Он стремится к самосовершенствованию и саморазвитию, обладает аналитическим умом, быстро думает, учится на ошибках 
других, но порой может и ошибаться. В то время как глупый человек предстает как умственно больной, сумасшедший, необразованный, нелепый и простоватый. Он с трудом или совсем не способен воспринимать и усваивать поступающую информацию, создает проблемы, совершает одни и те же ошибки. Его легко обмануть, и он не способен что-либо придумать, но ему постоянно везет [Дронь 2014: 14-15].

Необходимо отметить, что благодаря свойству отражения антонимические отношения наследуются у производящих слов производными, которые как бы отражают их в своей семантической структуре [Баско 1998: 55]. При рассмотрении оппозитивных лексем, характеризующих то или иное интеллектуальное свойство личности, выявляется парадигма, в структуре которой наглядно видно, имеются ли лакуны. На основании анализа такой парадигмы можно судить о потенциальных средствах компенсации лакун.

Проведение компонентного анализа в отношении выделенных оппозиций с использованием таких словарей, как «Cambridge dictionary and thesaurus», «Merriam-Webster's dictionary and thesaurus», «Универсальный англо-русский словарь», показало, что семантический комплекс рассматриваемой группы представлен следующим набором признаков:

1) интеллектуальное свойство личности brilliance/cleverness/stupidity, sanity/madness и т.п.;

2) признак человека, обладающего интеллектуальным свойством - talented/untalented, brilliant/clever/stupid и т.П.;

3) признак результата деятельности личности, обладающей интеллектуальным свойством - brilliant/clever/stupid, sane/mad, reasonable/unreasonable и т.п.;

4) характеристика человека, обладающего интеллектуальным свойством - an intellect / a mind / a stupid, ? / a madman и т.п. (здесь и далее вопросительный знак используется для обозначения лакуны);

5) так, как свойственно человеку, обладающему интеллектуальным свойством - sanely/crazily, wisely/foolishly, reasonably/unreasonably и т.п.;

6) проявлять/не проявлять интеллектуальное свойство - to reason $/$ ?. 
Далее мы подробно рассмотрим антонимическое гнездо (далее - АГ) «sane - mad» и покажем на его примере, как «белые пятна» в языке компенсируются фразеологизмами.

1) sanity/madness (интеллектуальное свойство): There are no words for the depths of loneliness I reached in that very thin border between sanity and madness (Context.reverso).- - Нет слов, чтобы описать глубину одиночества, которого я достиг на этой очень тонкой границе между здравомыслием и безумием.

2) sane/mad (признак человека, обладающего рассматриваемым свойством): They were written by a sane man pretending to be mad (Context.reverso).- Они были написаны здравомыслящим человеком, притворяющимся сумасшедшим.

3) sane/mad (признак результата деятельности человека, обладающего таким свойством): Now, in his heart, Ahab had some glimpse of this, namely: all my means are sane, my motive and my object mad (Мелвилл). - Где-то в глубине души Ахав догадывался о ней, он сознавал: все мои поступки здравы, цель и побуждение безумны.

4) madman (характеристика человека, обладающего таким свойством): But this madman could kill again at any moment (Context.reverso). - Но этот безумец мог убить снова в любой момент.

5) sanely (так, как свойственно человеку, обладающему таким свойством): To live in this world sanely there must be a radical change of the mind and of the heart (Context.reverso). - Чтобы жить в этом мире здраво, необходимо радикальное изменение ума и сердца.

6) проявлять/не проявлять такое свойство: ?

В рассматриваемой оппозиции «sane - mad» были выявлены лакуны при описании человека, обладающего разумом, находящегося в естественном состоянии сознания (субъекта) и предиката в отношении обеих противопоставленных ситуаций, а также признака действия, свойственного человеку с болезненным сознанием. Ряд следующих ФЕ может компенсировать «белые пятна» при выражении смысла «быть безумным, проявлять безумие»: to want two pence in the shilling - винтика не хватает; go (run/fall) mad/crazy/berserk/bananas - помешаться; loose one's marbles - слететь с катушек; to have got apartments to let, to have a tile, loose have bats in one's (the) belfry - не все дома; go out of one's 
mind/head - сойти с ума; be in one's second childhood - впасть в детство; have a loose screw, not to have all one's buttons (to have lost a button), have wheels in one's head-винтика не хватает; to be gone (a little light, weak, wrong) in the upper storey- рехнуться; be (go) off one's chump/nut/onion - сойти с ума; go bats, crackers, bonkers тронуться умом; при выражении смысла «не проявлять безумие»: have all one's button/marbles - в своем уме. Кроме того, в языке существует большое число ФЕ, характеризующих человека в естественном/измененном сознании, как с положительной, так и с отрицательной стороны: of sound mind, in one's senses, in one's right mind, all there - в здравом уме; (as) mad as a hatter/march hare - не в своем уме; balmy (barmy) on the crumpet (off one's crumpet) - выживший из ума; a bit off - не в своем уме; of unsound mind, not in one's right mind, out of one's mind - сумасшедший; off one's rocker/rocket/head/trolley/base - с приветом; up the pole, a little bit of the top - не в своем уме; soft in the head-сумасшедший; not playing with a full deck, be not (quite) all there - не все дома; be a button short - винтика не хватает; round the bend, to be crackers рехнувшийся. Фразеологизмы, оценивающие человека в измененном сознании: Bess (Jack) o'Bedlam- безумец; mental case - умалишенный; god's ape - идиот от рождения; hairy ape выродок; cousin Betty - слабоумный; natural fool - слабоумный от рождения; nut case - сумасшедший человек; crackpot - чокнутый человек.

По результатам проведенного анализа во всех рассматриваемых АГ были выявлены антонимические лакуны, наибольшее количество из которых (4) было найдено при характеристики человека с точки зрения таких признаков, как отсутствие выраженных природных способностей, отсутствие опытности при вынесении суждений и наличие сообразительности. Чаще лакуны обнаруживаются при оценке субъекта или назывании предиката ситуации, описывающего проявление интеллектуального свойства. В языке существуют следующие ФЕ, которые могут заполнить «пустые клетки» при описании компонента «обладать/не обладать природными способностями»: to be one of the brightest lights - хватать звезды с неба; set the Thames/world on fire - пороха не выдумает, to be not the brightest bulb in the chandelier/box- не отличаться умом. Субъект, проявляющий себя таким образом: no conjurer - пороха 
не выдумает. Лакуна «проявлять/не проявлять мыслительные способности» может быть заполнена при помощи таких ФЕ, как: have a lot of brains - ума палата; not to know beans/the first thing ни бельмеса не знать; to know as much about something as a pig about pineapples - не знать ни аза; not to have a brain in one's head, not have much between the ears - быть безмозглым. ФЕ со значением субъекта, имеющего данное свойство: brain boxочень умный; clever dick/clogs, smarty pants, know-it-all- зазнайка; smart Aleck, wiseacre - умник; birdbrain, the brain of a pigeonкуриные мозги; wooden head - дубина; dumb Dora - дура, Tom fool - дурак; a fool in grain - круглый дурак; horse's ass - тупица. Отсутствие лексической оппозиции оценки человека по наличию ума, образованности: a smart/tough cookie - смышленый, способный человек (акцент на способности быстро найти решение проблемы). Лакуна при назывании человека по разумности может быть заполнена при помощи ФЕ: clear head/mind - светлая голова. Предикат ситуаций - come to one's senses - браться за ум; to have a good head on one's shoulders быть разумным; lose one's senses/mind/reasonлишиться рассудка; take leave of senses - выжить из ума; go out of (one's) mind/senses - сойти с ума. Отсутствие лексической оппозиции оценки человека по сообразительности заполняются ФЕ: a Philadelphia lawyer - человек с острым умом; nobody's foolне промах; человек, который думает медленно: a slow couchтугодум; cabbage head- кочерыжка. Оппозиция предикатов выражается ФЕ: to have a quick wit/mind- иметь острый ум; to have a mind like a steel trap - иметь цепкий ум; be (very) quick in uptake - ловить на лету; для отсутствия проявления данного свойства: be slow on the uptake - медленно соображать. Лакуна в оппозиции по называнию опытного человека поддерживается следующими ФЕ: as wise as Solomon - ума палата; as wise as an owl - мудрый как сова; человек, который ум не использует: $d u m b$ Dora - дура; Tom fool дурак; cabbage head- кочерыжка. Для описания лакунарного предиката в данной ситуации можно использовать $\Phi E$ : to have one's head screwed (on the right way)иметь голову на плечах.

Таким образом, изучение денотативно-идеографической группы «Интеллектуальные свойства личности» в английском языке представляет интерес, поскольку позволяет выявить 
признаки и оценки в соответствующем фрагменте языковой картины мира, важные для носителей английского языка. Интеллектуальные свойства личности репрезентированы лексикофразеологическими единицами, распределенными по обеим сторонам оценочной шкалы. Каждая ситуация обладания тем или иным свойством представлена набором компонентов, называемых словами различных частей речи или фразеологическими единицами, способными быть средством заполнения существующих лакун.

\section{ЛИТЕРАТУРА}

1. Баско Н.В. Словообразовательная антонимия в русском языке (лингвистический и методический аспекты) // Язык, сознание, коммуникация. - М.: Диалог-МГУ, 1998, вып. 6. C. 51-59.

2. Быкова Г.В. Лакунарность как категория лексической системологии: монография. - М.: БГПУ, 2003. - 276 с.

3. Дронь Д.Ю. Лингвокогнитивный подход к проблеме категоризации интеллектуальных способностей человека : автореф. дис. ... канд. филол. наук. - Уфа, 2014. - 24 с.

4. Кшеновская У.Л., Стародубцева А.В. Языковые лакуны в публицистическом тексте и способы их элиминирования в процессе перевода // Вестник НГПУ, 2016, № 4 (32). - С. 154164.

5. Стернин И.А., Быкова Г.В. Концепты и лакуны // Языковое сознание: формирование и функционирование. - М., 1998. С. 55-67.

6. Стойкович Г.В., Стойкович Л.Ю. Некоторые аспекты структуры и содержания концепта «Интеллект человека» в английской лингвокультуре // Самарский научный вестник, 2013, №4 (5). - С. 146-149.

(C) Воронина Т.М., Черноскутова Д.А., 2021 г. 